\title{
Thyroid hormone dysfunctions affect the structure of rat thoracic aorta: a histological and morphometric study
}

\author{
S.M. Zaki ${ }^{1}$ M.F. Youssef ${ }^{2}$ \\ ${ }^{1}$ Anatomy Department, Faculty of Medicine, Cairo University, Cairo, Egypt \\ ${ }^{2}$ Histology Department, Faculty of Medicine, Cairo University, Cairo, Egypt \\ [Received 12 May 2013; Accepted 2 July 2013]
}

Background: There are limited data about the influence of hypothyroidism and hyperthyroidism on the connective tissue component and smooth muscle cells of the thoracic aorta. The aim was to study the histological changes of the wall of the thoracic aorta in the hypothyroid and hyperthyroid rats. Morphometric measurements were also done.

Materials and methods: Thirty adult rats were used. They were divided into control, hyperthyroid, and hypothyroid groups. Each group consisted of 10 rats. The animals were sacrificed at the end of 8 weeks and the descending aorta was excised. Sections were stained with haematoxylin and eosin, orcein and Masson's trichrome stains. The morphometric measurement included: number of smooth muscle cell nuclei, number of the elastic lamellae, thickness of the tunica media, elastic fibre optic density, and relative collagen area.

Results: Atheromatous plagues had been observed in the hyperthyroid group. Thinning and rupture of the elastic lamellae had been observed in the hypothyroid group; these were accompanied with intimal ulceration and aortic dissection. The average number of smooth muscle cell nuclei in the hyperthyroid group had doubled and tripled compared to their fellows in the control and hypothyroid groups, respectively. The thickness of the tunica media increased in the hyperthyroid and hypothyroid groups by $75 \%$ and $35 \%$. In addition, the relative collagen area increased in the previously mentioned groups by $142 \%$ and $120 \%$, respectively. On the other hand, the mean elastic fibre optic density decreased in both groups by $30 \%$. Conclusions: Structure wall affections of the intima and media of the descending aorta were associated with the thyroid hormone dysfunctions. These changes were more severe in the hypothyroid group. (Folia Morphol 2013; 72, 4: 333-339)

Key words: hyperthyroidism, hypothyroidism, descending aorta

\section{INTRODUCTION}

Thyroid disease affects nearly $10 \%$ of the population [4]. Alterations in thyroid hormone levels have a profound impact on the cardiovascular system [13]. Cardiovascular dysfunction has been associated with both hyperthyroidism and hypothyroidism [13, 20]. In hypothyroidism, the cardiovascular dysfunctions are decreased cardiac contractility, cardiac output, heart rate, and left ventricular compliance with increased total peripheral vascular resistance [21]. Haemodynamic effects of hyperthyroidism are opposite to those of hypothyroidism [6]; they are in the form 
of increased cardiac muscle contractility, heart rate, cardiac output, red cell number, blood volume, and decreased total peripheral resistance [22]. Aortic dissection, aortic aneurysm and atherosclerosis had been reported with hypothyroidism $[9,18]$.

Up to our knowledge, there are limited data about the influence of hypothyroidism and hyperthyroidism on the connective tissue component and smooth muscle cells of the thoracic aorta, as most of the literatures are concentrating their works on the mechanical affection of aorta in thyroid gland diseases, using the noninvasive techniques. In addition, the data on the histological composition in human aortas of hypothyroid patients are scarce [20].

We hypothesised that thyroid hormone dysfunctions have structural effects on the thoracic aorta. Therefore, we aimed in this work to study the histological changes of the wall of the thoracic aorta in the hypothyroid and hyperthyroid albino rats. Morphometric measurements were also done using the image analyser.

\section{MATERIALS AND METHODS}

Thirty adult male Sprague Dawley rats weighing 200-250 $\mathrm{g}$ were used. The animals were acclimatised to standard laboratory conditions (12:12-h light-dark cycle, temperature $20^{\circ} \mathrm{C}$, relative humidity $55 \%$, and central ventilation). They were fed ad libitum and allowed free water supply. The animals were raised in the animal house of the Faculty of Medicine, Cairo University, which follows its guideline, and also according to the guideline of the National Institute of Health Guide.

The animals were divided into 3 groups: control group, hyperthyroid group and hypothyroid group. Each group consisted of 10 rats.

Hyperthyroidism was induced by the administration of L-thyroxine (L-thyroxine sodium salt pentahydrate, Sigma Chemicals, St. Louis, Missouri). L-thyroxine $(1 \mathrm{mg} / 100 \mathrm{~mL}$ ) was added to the drinking water daily for 8 weeks [16]. The oral treatment induced hyperthyroidism without causing the stress provoked by the daily injections [16]. This method was proved to be effective in induction of hyperthyroidism [25].

Hypothyroidism was induced by the administration of propylthiouracil (PTU, Sigma Chemicals, St. Louis, Missouri). Propylthiouracil $(0.04 \mathrm{~g} / 100 \mathrm{~mL}$ ) was added to the drinking water daily for 8 weeks [17]. Such concentration used resulted in a moderate hypothyroidism [23].

Both hypothyroidism and hyperthyroidism were confirmed by determining serum concentration of total $\mathrm{T}_{3}$ and total $\mathrm{T}_{4}$. This was accomplished in the laboratory by use of radioimmunoassay kits [8].

The animals were sacrificed after 8 weeks of agents' administration by a high dose of ether. The thoracic cavity was opened through a median sternotomy. The descending aorta was excised with extreme care to avoid damage to the aortic wall.

\section{Light microscopic study}

Parts of the descending aorta were fixed in phosphate-buffered formaldehyde solution and routinely processed for paraffin sections. At least 4-8 sections were prepared from each specimen. The sections were separated by a given distance $20 \mu \mathrm{m}$ to obtain roughly random choice of sections for morphometric measurements. The sections were stained with haematoxylin and eosin (H\&E), orcein stain for elastic fibers detection, and Masson's trichrome for collagen staining. The prepared sections were examined and photographed using a Canon digital camera (Canon, Japan) attached to IBM computer system.

\section{Morphometric study}

The sections were examined using Leica Qwin 500 image analysis software on IBM operated computer system (Leica Microsystems, Wetzlar, Germany). Thirty preparations in each group were subjective to the quantitative studies:

1. Number of smooth muscle cell nuclei/field;

2. Number of the elastic lamellae/field;

3. Thickness of the tunica media: this measurement includes both the thickness of the intima and media, as it is difficult to draw a clear border between intima and media in an elastic type artery;

4. Elastic fibre optic density: this was done by transforming the image into grey image and then masking the positive areas by blue binary colour. The parameters chosen were the number of pixels, the sum of grey and mean grey areas. The optical density was expressed in the form of mean grey area that was obtained by the following equation:

$$
\text { Mean grey area }=\frac{\text { Number of pixels }}{\text { Sum of grey area }}
$$

5. The relative collagen area was measured inside a standard measuring frame of a known area. The collagen fibres were selected and masked by blue binary colour. Then the area of the blue binary colour was measured and expressed as an area per cent in relation to the area of the standard measuring frame of a known section area. 


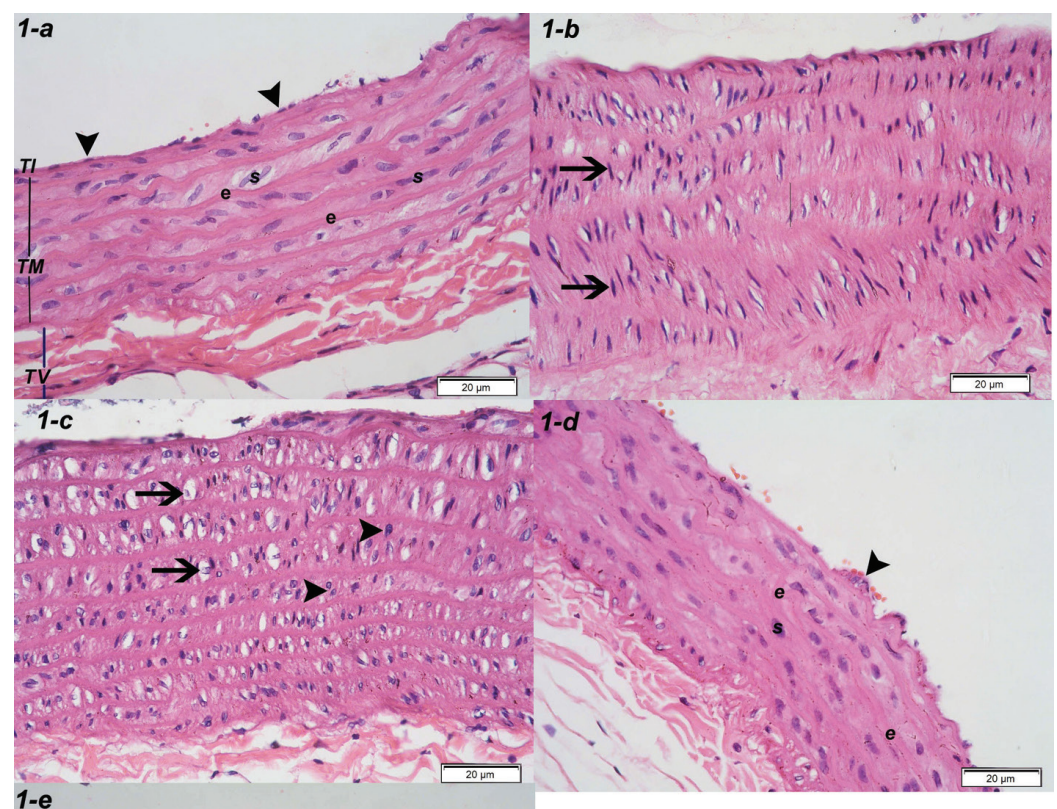

$1-e$

Figure 1. Representative histological sections of the wall of the thoracic aorta stained with $\mathrm{H} \& \mathrm{E}(\times 400) ; \mathrm{A}$. Endothelial cells (arrowheads) line the tunica intima (TI), elastic lamellae (e), and smooth muscle cell nuclei (s) of the tunica media (TM), and the tunica adventitia (TV) of the control group; B. Smooth muscle cell nuclei (arrows) of the tunica media of the control group (a longitudinal section); C. Degeneration (arrows), round-shape (arrowheads) and hyperplasia of the smooth muscle cell nuclei of the hyperthyroid group tunica media (a longitudinal section); D. Atheromatous plaque (arrowhead), lamellae of elastic fibres (e), and smooth muscle cell nuclei (s) of the tunica media of the hyperthyroid group; E. Lamellae of elastic fibres (e) and smooth muscle cell nuclei (s) of the tunica media of the hypothyroid group.

The data were collected and studied using analysis of variance (one way ANOVA), followed by post hoc Bonferroni test to compare between the studied groups using SPSS v. 20 statistical program. The quantitative data were examined by Kolmogrov Smirnov test for normality. Level of significance was considered at $p$-value $<0.05$.

\section{RESULTS}

\section{General microscopic structure of rat descending} aorta in control and experimental groups

The H\&E-stained sections of the control group showed typical 3 tunicae of the thoracic aorta: the tunica intima with the endothelial cells lining the tunica media with the normal arrangement of elastic lamellae and the horizontally oriented spindle-shaped nuclei of the smooth muscle cells, and finally the tunica adventitia (Figs. 1A, B).

All the rats of the hyperthyroid group presented with morphological alterations of the smooth muscle cell nuclei of the tunica media. The tunica media showed degeneration, round-shape and hyperplasia of the smooth muscle cell nuclei (Fig. 1C).
In addition, atheromatous plaques were observed in some animals (Fig. 1D). In the hypothyroid group, the histological structure of aorta was similar to that of the control group (Fig. 1E).

\section{Histological structure of rat descending aorta in control and experimental groups, as revealed by orcein and Masson's trichrome staining}

The orcein stained sections showed the arrangement of the elastic lamellae of different studied groups, with relatively wide gaps between the elastic lamellae in the hypothyroid group (Figs. 2A-C).

As compared with the control group (Fig. 3A), an increase of the volume of collagen fibres between the elastic lamellae in aorta's wall was observed in both the hyperthyroid (Fig. 3B) and hypothyroid (Fig. 3C) groups, using the Masson's trichrome staining. Intimal ulceration had been observed in the hypothyroid group (Fig. 3D). In addition, thinning and ruptures of the elastic lamellae were observed in some rats of this group; this was accompanied by the presence of wide gaps between the elastic lamellae (Fig. 3C). Finally, severe structural changes 


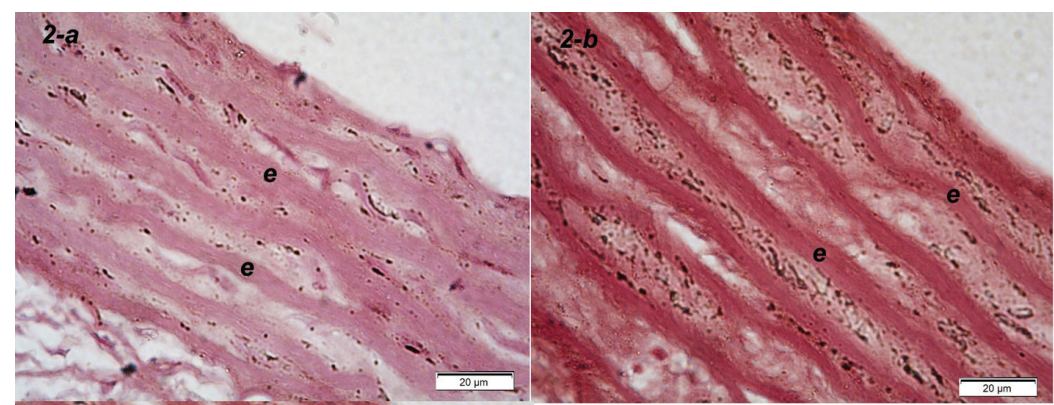

Figure 2. Representative histological sections of the wall of the thoracic aorta stained with orcein stain showing the lamellae of elastic fibers (e) of the control group (A), the hyperthyroid group (B) and the hypothyroid group (C). Note the gapping (G) between the elastic lamellae in the hypothyroid group $(\times 1000)$.

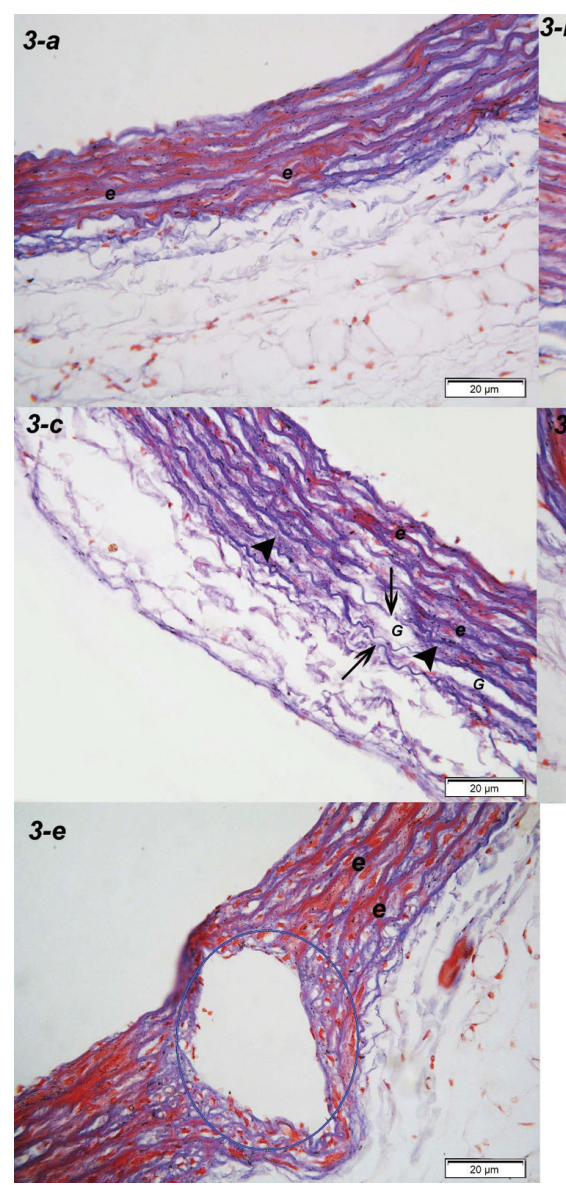

Figure 3. Representative histological sections of the wall of the thoracic aorta stained with Masson's trichrome stain ( $\times 400)$; A. Elastic lamellae (e) of the control group; B. Increase of the collagenous tissue (arrowheads) between the elastic lamellae (e) of the hyperthyroid group; C. Increase of the collagenous tissue (arrowheads), thinning of the elastic lamellae (arrows) with wide gaps $(\mathrm{G})$ between the lamellae (e) of the hypothyroid group; $\mathbf{D}$. Thinning and ruptures of the elastic lamellae (thin arrows) was accompanied by intimal ulceration (thick arrows) and wide gaps (G) between the lamellae (e) of the hypothyroid group; E. Abnormal arrangement and fusion (circle) of the elastic lamellae (e) of the hypothyroid group.

were observed in 2 rats of the hypothyroid group in the form of abnormal arrangement and fusion of the elastic lamellae (Fig. 3E).

Total levels of $T_{3}$ and $T_{4}$ in different groups had been recorded in Table 1.

\section{Morphometric evaluation of the aorta structure}

Structural alterations of thoracic aorta structure were observed in both hyperthyroid and hypothyroid groups in comparison to the control group. The mean number of smooth muscle cell nuclei in the hyperthy- 
Table 1. Data for total levels of $T_{3}$ and $T_{4}$ in different groups

\begin{tabular}{lccc}
\hline & Control group & Hypothyroid group & Hyperthyroid group \\
\hline Total $\mathrm{T}_{3}$ levels $[\mathrm{ng} / \mathrm{mL}]$ & $0.3 \pm 0.01$ & $0.04 \pm 0.01$ & $3.4 \pm 0.5$ \\
Total $\mathrm{T}_{4}$ levels $[\mathrm{ng} / \mathrm{mL}]$ & $35.9 \pm 6.1$ & $19.9 \pm 1.5$ & $300 \pm 20.6$ \\
\hline
\end{tabular}

Table 2. Measurements of the aortic media components in different groups

\begin{tabular}{lccc}
\hline & Control group & Hypothyroid group & Hyperthyroid group \\
\hline Number of smooth muscle cell nuclei/field & $91.5 \pm 2.6$ & $67.6 \pm 3.7$ & $213 \pm 4.2$ \\
Number of elastic lamellae/field & $6.9 \pm 0.3$ & $5.4 \pm 0.5$ & $7.5 \pm 0.5$ \\
Media thickness $[\mu \mathrm{m}]$ & $61.6 \pm 3.4$ & $82.9 \pm 3.1$ & $107.7 \pm 5.8$ \\
Elastic fibre optic density & $0.3 \pm 0.04$ & $0.2 \pm 0.01$ & $0.2 \pm 0.01$ \\
Relative collagen area & $19.4 \pm 3.7$ & $42.7 \pm 5$ & $47.1 \pm 7.2$ \\
\hline
\end{tabular}

Table 3. Comparison between the aortic media components in different groups

\begin{tabular}{|c|c|c|c|c|c|c|}
\hline Dependent variable & (I) Groups & (J) Groups & $\begin{array}{l}\text { Mean differ- } \\
\text { ence (I-J) }\end{array}$ & SE & $P$ value & F value \\
\hline \multirow{3}{*}{$\begin{array}{l}\text { Number of smooth muscle } \\
\text { cell nuclei/field }\end{array}$} & \multirow{2}{*}{ Control } & Hypothyroidism & 23.9 & 1.6 & $0.000^{*}$ & \multirow{3}{*}{4651} \\
\hline & & Hyperthyroidism & -121.5 & 1.6 & $0.000^{*}$ & \\
\hline & Hypothyroidism & Hyperthyroidism & -145.4 & 1.6 & $0.000^{*}$ & \\
\hline \multirow{3}{*}{$\begin{array}{l}\text { Number of elastic } \\
\text { lamellae/field }\end{array}$} & \multirow{2}{*}{ Control } & Hypothyroidism & 1.5 & 0.2 & $0.000^{*}$ & \multirow{3}{*}{151} \\
\hline & & Hyperthyroidism & -0.6 & 0.2 & $0.02^{*}$ & \\
\hline & Hypothyroidism & Hyperthyroidism & -2.1 & 0.2 & $0.000^{*}$ & \\
\hline \multirow[t]{3}{*}{ Elastic fibre optic density } & \multirow{2}{*}{ Control } & Hypothyroidism & 0.09 & 0.1 & $0.000^{*}$ & \multirow{3}{*}{42.9} \\
\hline & & Hyperthyroidism & 0.1 & 0.1 & $0.000^{*}$ & \\
\hline & Hypothyroidism & Hyperthyroidism & 0.01 & 0.01 & 1 & \\
\hline \multirow[t]{3}{*}{ Relative collagen area } & \multirow{2}{*}{ Control } & Hypothyroidism & -23.3 & 2.4 & $0.000^{*}$ & \multirow{3}{*}{73} \\
\hline & & Hyperthyroidism & -27.7 & 2.4 & $0.000^{*}$ & \\
\hline & Hypothyroidism & Hyperthyroidism & -4.4 & 2.4 & 0.2 & \\
\hline \multirow{3}{*}{ Media thickness $[\mu \mathrm{m}]$} & \multirow{2}{*}{ Control } & Hypothyroidism & -21.3 & 1.9 & $0.000^{*}$ & \multirow{3}{*}{286.5} \\
\hline & & Hyperthyroidism & -46.0 & 1.9 & $0.000^{*}$ & \\
\hline & Hypothyroidism & Hyperthyroidism & -24.7 & 1.9 & $0.000^{*}$ & \\
\hline
\end{tabular}

${ }^{*}$ Statistically significant

roid group was nearly doubled and tripled compared to the control and hypothyroid groups, respectively (Tables 2, 3). However, the number of myocytes' nuclei in the aorta's wall of hypothyroid rats was decreased by $25 \%$ as compared to the control group $(p=0.0001)$.

The average number of elastic lamellae in the hyperthyroid group was not different compared to that of the control group, and was 38\% more than that of the hypothyroid group $(p<0.05)$; moreover, their mean number had been decreased by $21 \%$ in the hypothyroid group compared to that of the control group $(p=0.000)$ (Tables 2, 3).

The thickness of the tunica media of both hyperthyroid and hypothyroid groups increased by $75 \%$ and $35 \%$, respectively, when they were compared with their similarities in the control group; however, the thickness in the hyperthyroid group was nearly more than that of the hypothyroid group by $30 \%(p=0.000)$. 
The mean elastic fibre optic density had been decreased in both hyperthyroid and hypothyroid groups by nearly $30 \%$ compared to their fellows in the control group $(p=0.000)$; however, no difference had been observed between the hyperthyroid and hypothyroid groups $(p=1)$.

The relative collagen area had been increased in the hyperthyroid group by $142 \%$ when compared to that of the control group, and it also had been increased in the hypothyroid group by $120 \%$ when compared to that of the control group. Nearly no difference had been observed between the hyperthyroid and the hypothyroid groups.

\section{DISCUSSION}

The aortic wall is composed of elastin, collagen, and smooth muscle. The viscoelastic properties of the arterial wall depend on a passive component due to elastic and collagenous connective tissue and on an active component due to smooth muscle activity [2]. The aorta is from the elastic type arteries with a higher proportion of elastic fibres and only a small quantity of smooth muscle cells [2].

In the current study, degeneration with change shape of the smooth muscle cell nuclei had been observed in the hyperthyroid group. These nuclear changes seemed to be models on which aortic dissection may occur [12]. In addition, the mean number of the smooth muscle cell nuclei had been doubled in the hyperthyroid group compared to the control group. This increase seemed to be related to the strong mitogenic effect of $\mathrm{T}_{3}$ and its capability of cell proliferation in rats [29]. Wang and Sun [29] added, that $\mathrm{T}_{3}$ induced the rat aorta smooth muscle proliferation by up-regulating a gene called $\mathrm{NOX}_{1}$. The smooth muscle cells of the aorta are responsible for the production of extracellular matrix [19]. They make substantial contributions to the elastic lamellar architecture through their production of elastin, collagen, and other matrix proteins [24]. They also participate in matrix remodelling through localised expression of various proteinases and their inhibitors [3].

The decrease in the elastic fibre optic density and the increase of the area \% of collagen fibres had been observed in both hyperthyroid and hypothyroid groups. These structural changes affect the mechanical characteristics of the aorta. Sokolis el al. [27] reported that at low pressures, passive stiffness of the aorta is determined by the elastin content, and at high pressures, the stiffness is determined by the collagen content. The previous authors added that at physiologic pressure, the stiffness is determined by both elastin and collagen content [27]. The impairment of the elastic properties of the aorta and the marked increase in its collagen content are associated mostly with increased stiffness of the aorta and decrease of its distensibility $[20,30]$. The impairment of aortic elastic properties in hyperthyroidism may be due to the direct effect of the thyroid hormones on the aorta and due to the modulate effects of thyroid hormones on the vascular renin-angiotensin system [1].

One important finding in the current study was the presence of atheromatous plagues in the aortic wall of the hyperthyroid group. It was reported that the increased stiffness of the aorta was associated with the development of cardiovascular disease [28]. The change of the aortic stiffness contributed indirectly to the development of atherosclerosis, through the effects of cyclic stress on arterial wall histological alterations $[14,15]$.

Another important finding in the hypothyroid group was the presence of aortic dissection. Intimal wall tear had been observed in this group. This tear allowed the shear forces of blood flow to dissect the intima from the media and to penetrate the diseased media with resultant rupture of aortic lamellae. Beside the ruptured aortic lamellae, wide gaps between the elastic lamellae had been observed in the previously mentioned group. Many investigators contributed the association between hypothyroidism and aortic pathologies, such as aortic dissection, to the effect of hypothyroidism on the mechanical performance of the aorta, the disturbance of the mechanical properties of the aorta, and to the altered mucopolysaccharide turnover leading to weakening of the aortic wall $[5,26]$. The occurrence of aortic dissection in cases of hypothyroidism is a very important finding, as the mortality rate associated with thoracic aortic dissection is high [10], leading to a $68 \%$ mortality within 48 hours [7].

We have observed the increase of the thickness of the thoracic aorta tunica media in the hyperthyroid and hypothyroid groups. This increase was mostly secondary to the increased relative collagen area that had been observed in both groups. In addition, the increased thickness of the tunica media may be partly due to the increased medial smooth muscle cells observed in the hyperthyroid group. It was reported that aortic intima-media thickness was an earlier marker of preclinical atherosclerosis [11], which had been observed in the hyperthyroid group. 


\section{CONCLUSIONS}

We concluded that structure wall affections of the intima and media of the thoracic aorta were associated with thyroid hormone dysfunctions in the albino rats. These changes were more severe and profound in the hypothyroid group.

We recommend the routine follow-up of the thoracic aorta in patients with thyroid hormone dysfunction - especially the hypothyroid one - with noninvasive maneuver like Doppler for early detection of the medial wall aortic affection, so that severe pathological complications can be avoided.

\section{REFERENCES}

1. Akcay M, Akcay E, Yeter E, Durmaz T, Keles T, Bayram NA, Yuksel I, Yuksel Kalkan G, Ayhan H, Simavli H, Simsek S, Bozkurt E (2011) Aortic elastic properties are impaired in patients with Graves' ophtalmopathy. Vasa, 40: 41-48.

2. Barenbrock M, Spieker C, Witta J, Evers S, Hoeks AP, Rahn KH, Zidek W (1996) Reduced distensibility of the common carotid artery in patients treated with ergotamine. Hypertension, 28: 115-119.

3. Bendeck MP, Zempo N, Clowes AW, Galardy RE, Reidy MA (1994) Smooth muscle cell migration and matrix metalloproteinase expression after arterial injury in the rat. Circ Res, 75: 539-545.

4. Canaris GJ, Manowitz NR, Mayor G, Ridgway EC (2000) The Colorado thyroid disease prevalence study. Arch Intern Med, 160: 526-534.

5. Cigarroa JE, Isselbacher EM, DeSanctis RW, Eagle KA (1993). Diagnostic imaging in the evaluation of suspected aortic dissection. Old standards and new directions. N Engl J Med, 328: 35-43.

6. Danzi S, Klein I (2004) Thyroid hormone and the cardiovascular system, Minerva Endocrinol, 29: 139-150.

7. Erbel R, Alfonso F, Boileau C, Dirsch O, Eber B, Haverich A, Rakowski H, Struyven J, Radegran K, Sechtem U, Taylor J, Zollikofer Ch (2001) Diagnosis and management of aortic dissection. Eur Heart J, 22: 1642-1681.

8. Gilbert ME. Impact of low-level thyroid hormone disruption induced by propylthiouracil on brain development and function (2011) Toxicol Sci, 124: 432-445.

9. Gutierrez PS, Pereira MA, Oliveira RC, Stolf NA, Higuchi M (2004) Thyroid hormone levels in patients with aortic dissection: comparison with controls and correlation with the percentage of the aortic media composed of myxoid deposits. Arq Bras Cardiol, 82: 134-8, 29-33.

10. Hagan PG, Nienaber CA, Isselbacher EM, Bruckman D, Karavite DJ, Russman PL, Evangelista A, Fattori R, Suzuki T, Oh JK, Moore AG, Malouf JF, Pape LA, Gaca C, Sechtem U, Lenferink S, Deutsch HJ, Diedrichs H, Marcos y Robles J, Llovet A, Gilon D, Das SK, Armstrong WF, Deeb GM, Eagle KA (2000) The International Registry of Acute Aortic Dissection (IRAD): new insights into an old disease. JAMA, 283: 897-903.

11. Harrington J, Peña AS, Gent R, Hirte C, Couper J (2010) Aortic intima media thickness is an early marker of atherosclerosis in children with type 1 diabetes mellitus. J Pediatr, 156: 237-241.

12. Hartman JD, Eftychiadis AS (1990) Medial smooth-muscle cell lesions and dissection of the aorta and muscular arteries. Arch Pathol Lab Med, 114: 50-61.
13. Klein I, Ojamaa K (2001) Thyroid hormone and the cardiovascular system, N Engl J Med, 344: 501-509.

14. Laurent S, Boutouyrie P, Asmar R, Gautier I, Laloux B, Guize L, Ducimetiere $P$, Benetos A (2001) Aortic stiffness is an independent predictor of all-cause and cardiovascular mortality in hypertensive patients. Hypertension, 37: 1236-1241.

15. Malayeri AA, Natori S, Bahrami H, Bertoni AG, Kronmal R, Lima JA, Bluemke DA (2008) Relation of aortic wall thickness and distensibility to cardiovascular risk factors (from the Multi-Ethnic Study of Atherosclerosis [MESA]). Am J Cardiol, 102: 491-496.

16. Martí-Carbonell MA, Garau A, Sala-Roca J, Balada F (2012) Effects of adult dysthyroidism on the morphology of hippocampal granular cells in rats. Acta Neurobiol Exp, 72: 230-239.

17. McAllister RM, Luther KL, Pfeifer PC (2000) Thyroid status and response to endothelin-1 in rat arterial vessels. Am J Physiol Endocrinol Metab, 279: E252-E258.

18. Mitu F, Cojocaru E, Tamba B, Leon MM (2012) [Prevalence of cardiovascular diseases to the patients with hypothyroidism]. Rev Med Chir Soc Med Nat lasi, 116: 413-418.

19. Moulakakis KG, Poulakou MV, Paraskevas KI, Dontas I, Vlachos IS, Sokolis DP, Dosios T, Karayannacos PE, Perrea D (2007) Hyperthyroidism is associated with increased aortic oxidative DNA damage in a rat model. In Vivo, 21: 1021-1026.

20. Moulakakis KG, Sokolis DP, Perrea DN, Dontas I, Dosios T, Poulakou MV, Mylonas SN, Dimitriou CA, Karayannacos PE (2010) The effects of hypothyroidism on the mechanical properties and histomorphological structure of the thoracic aorta. Angiology, 61: 259-268.

21. Obuobie K, Smith J, Evans LM, John R, Davies JS, Lazarus JH (2002) Increased central arterial stiffness in hypothyroidism. J Clin Endocrinol Metab, 87: 4662-4666.

22. Obuobie K, Smith J, John R, Davies JS, Lazarus JH (2002) The effects of thyrotoxicosis and its treatment on central arterial stiffness. Eur J Endocrinol, 147: 35-40.

23. Pantos C, Malliopoulou V, Mourouzis I, Sfakianoudis K, Tzeis S, Doumba P, Xinaris C, Cokkinos AD, Carageorgiou H, Varonos DD, Cokkinos DV (2003) Propylthiouracil-induced hypothyroidism is associated with increased tolerance of the isolated rat heart to ischaemia-reperfusion. J Endocrinol, 178: 427-435.

24. Rasmussen LM, Wolf YG, Ruoslahti E (1995) Vascular smooth muscle cells from injured rat aortas display elevated matrix production associated with transforming growth factor-beta activity. Am J Pathol, 147: 1041-1048.

25. Sala-Roca J, Estebanez-Perpina E, Balada F, Garau A, Martí-Carbonell MA (2008) Effects of adult dysthyroidism on the morphology of hippocampal neurons. Behav Brain Res, 188: 348-354.

26. Shigeta O, Makuuchi H, Kaneko Y, Takuma S, Konishi T, Omura M (1994) [A case of acute aortic dissection associated with myxedema]. Nihon Kyobu Geka Gakkai Zasshi, 42: 1096-1100.

27. Sokolis DP, Kefaloyannis EM, Kouloukoussa M, Marinos E, Boudoulas H, Karayannacos PE (2006) A structural basis for the aortic stress-strain relation in uniaxial tension. J Biomech, 39: 1651-1662.

28. Van Bortel LM, Struijker-Boudier HA, Safar ME (2001) Pulse pressure, arterial stiffness, and drug treatment of hypertension. Hypertension, 38: 914-921.

29. Wang $X$, Sun $Z$ (2010) Thyroid hormone induces artery smooth muscle cell proliferation: discovery of a new TRalpha1-Nox1 pathway. J Cell Mol Med, 14: 368-380.

30. Yurtdaş M, Gen R, Ozcan T, Aydın MK (2013) Assessment of the elasticity properties of the ascending aorta in patients with subclinical hypothyroidism by tissue Doppler imaging. Arq Bras Endocrinol Metabol, 57: 132-138. 